\title{
Use of recycled fillers in bituminous mixtures for road pavements
}

\author{
Dario Topinia $^{\mathrm{a}, *}$, Emanuele Toraldo ${ }^{\mathrm{a}, 1}$, Luca Andena ${ }^{\mathrm{b}, 2}$, Edoardo Mariani $^{\mathrm{a}, 3}$ \\ ${ }^{a}$ Department of Civil and Environmental Engineering, Politecnico di Milano, 32 Piazza Leonardo Da Vinci, 20133 \\ Milano, Italy \\ ${ }^{\mathrm{b}}$ Department of Chemistry, Materials and Chemical Engineering “Giulio Natta”, Politecnico di Milano, 32 Piazza \\ Leonardo Da Vinci, 20133 Milano, Italy
}

\begin{abstract}
This paper reports the results of a laboratory investigation on the use of recycled fillers in bituminous mixtures for road pavements. The fillers were obtained by crushing and sieving $(0.00-$ $0.063 \mathrm{~mm}$ ) Stabilized Bottom Ashes from municipal waste incinerators and Electric Arc Furnace Steel Slags. Moreover, a currently used calcareous filler was included in the research for comparative purposes. Two filler dosages were considered in the experiments.

Laboratory tests aimed at investigating compaction properties, volumetric characteristics, and mechanical performance of the bituminous mixtures.

The results suggest that both types of recycled filler are suitable to be used in bituminous mixtures, also demonstrating that in certain conditions the investigated fillers increase the performance of the corresponding mixtures in comparison to standard (calcareous) filler.
\end{abstract}

Keywords: bituminous mixtures, recycled filler, bottom ashes, electric arc furnace steel slags, road performances.

\footnotetext{
* Corresponding author. Tel.: +39 0223996605

E-mail addresses: dario.topini@polimi.it (D. Topini), emanuele.toraldo@polimi.it (E. Toraldo), luca.andena@polimi.it (L. Andena), edoardo.mariani@polimi.it (E. Mariani).

${ }^{1}$ Tel.: +390223996618

${ }^{2}$ Tel.: +3902 23993289

${ }^{3}$ Tel.: +3902 23996619
} 


\section{Introduction}

In recent years, waste material recycling became a theme of growing importance. The European Union itself, through its directives, keeps pushing in this direction (Directive 2008/98/EC) and transportation infrastructures are expected to comply to a general perspective of recycling and environmental compatibility [1-3], in view of a circular economy.

Indeed, during the last two decades, to reduce consumption of new sources, thus limiting the environmental impact of new constructions, the research community in the field of civil engineering addressed its efforts to recycle, reclaim and reuse waste materials in new products [4]. In this context, a crucial role is played by transportation infrastructures since their new construction and rehabilitation consume a lot of lithic materials. Actually, several researches emphasize the use of new techniques in which recycled materials are used, involving all the layers composing a transportation infrastructure. For instance, recycled aggregates deriving from demolition of end of life pavements are currently used as skeleton for foundation layers [5] and for base or intermediate bituminous layers [6] into airport [7-8] and road infrastructures [9-10].

Another field of research focuses on the re-use of waste materials in pavement layers. Authors have demonstrated that it's possible to use Stabilized Bottom Ashes and Electric Arc Furnace Steel Slags in pavements without leading to any kind of distress; they also demonstrated the environmental suitability through chemical analysis [11-13]. This currently widespread practice represents, indeed, a potential solution to two important and delicate issues: the growing problem of dismissing these industrial by-products and the need to find alternative sources to the traditional quarried stone materials used for road construction. For some years now, authorities, researchers and practitioners have addressed their efforts toward solving the open issue of a proper management of municipal solid waste, especially in countries with a high population density. In this context, incinerators play a decisive role because they combine the potential advantages of energy production and volume reduction up to $90 \%$ of waste materials [14-15]; obviously, the incinerator products, fly and bottom ashes, must be properly treated to avoid any health risk. Nowadays these products find use in civil engineering applications; in particular, bottom ashes are currently used as artificial aggregates for cement concretes [16-18] and bituminous mixtures [1920]. Another waste product comes from industrial steel production, which involves two main processes: the integral cycle, which starts from mineral iron, and the electric cycle, which uses scrap metal [21]. Approximately $63 \%$ of the steel produced in Italy comes from Electric Arc Furnaces (EAF), which, in addition to the steel, produce more than 6 million tons of slag annually. 
From a technical point of view, EAF slags possess physical, chemical and mechanical properties that make them suitable for use in road construction [22].

Arguably, more research is required to provide solutions to this growing demand, which must be technically feasible as well as economically and environmentally sustainable.

In this context, and particularly referring to bituminous mixtures for road and airport pavements, in which the use of recycled aggregates is becoming a common practice, recycled fillers are not frequently employed and their effectiveness still needs to be assessed. To contribute to the knowledge in this field, the authors performed the investigation herein described, in which two non-conventional (recycled) fillers were compared against a calcareous one.

\subsection{Background and literature review}

As mentioned above, the use of recycled fillers for bituminous mixtures is still at the research stage and the lack of knowledge about the use of this type of fillers is demonstrated by the scarce literature available on this topic. In this section, we present some works of interest.

Sargin et al. [23], for instance, studied the influence of rice husk ash (RHA) as filler in bituminous mixtures; test results showed that mixtures including 50\% RHA and 50\% limestone (LS) guarantee a suitable Marshall Stability (MS). Even if authors believe that MS is not a proper indicator of the performance of bituminous mixtures, Sargin's research demonstrated that, especially in areas where its availability is large, RHA can be used as a replacement filler in asphalt concrete mixtures instead of limestone.

Rongali et al. [24] reported the benefits of composite of fly ash and plastic waste in bituminous mixture for construction of flexible pavement. They demonstrated that fly ash can be used as filler in bituminous mixtures, and the corresponding performance increase properties of bituminous mixtures by coating fly ash with plastic waste, particularly in terms of rutting.

Dhir et al. [25], while studying cleaned oil-drill cuttings used as filler in bituminous mixtures, underlined that the assessment of bituminous mixtures by the ring and ball test indicated that all but one of the four cleaned oil-drill cutting samples investigated were more effective than the reference limestone filler. All fillers produced homogeneous mixtures with bitumen and proved to have potential to partially, or even fully, replace newly quarried limestone aggregates.

Chen et al. [26] showed that it is possible to use even recycled fine aggregates powder as filler in bituminous mixture. In this study, recycled fine aggregates powder (RFAP) is used as filler in asphalt mixture by totally replacing conventional limestone powder (LP). Firstly, the properties of 
RFAP is studied by X-ray diffraction (XRD), Scanning Electron Micros-copy (SEM) and X-ray fluorescence spectroscopy (XRF). Then the indirect tensile strength and modulus tests, three-point bending tests, dynamic creep tests and fatigue tests are conducted to compare the properties between asphalt mixtures with RFAP and traditional asphalt mixture with LP. Results indicate that RFAP can improve the properties of asphalt mixture, such as including water sensitivity and fatigue resistance. However, it may cause a little decrease of the low-temperature performance. All the results indicate that the RFAP can be used in asphalt pavement, especially in hot regions.

Pasetto et al. [27], studied the rheological characterization of warm-modified bituminous mastics containing electric arc furnace steel slags. Such innovative material applied at lower temperatures and containing warm additives and steel slag should be able to guarantee at least the same performance of traditional bituminous mixtures, thus assuring acceptable mechanical properties and durability.

Arabani et al. [28], examined the use of various waste materials as filler in bituminous mixtures. They investigated waste glass powder (WGP), waste brick powder (WBP), rice husk ash (RHA) and stone dust (control mixture) as filler, optimizing the bitumen content. Their experimentation was based on Marshall stability test, indirect tensile stiffness modulus and indirect tensile fatigue tests. The results indicated that WGP and WBP increase significantly the fatigue life and, generally, the mixtures performance. In addition, they demonstrated that there was no appreciable difference in the performance of RHA and control mixture.

Recently, López-López et al. [29], explored the possibility of using bottom ash from thermal power plant and lime as filler in bituminous mixtures. The study focused on the characterization of chemical and physical properties of Bottom Ash (BA) and on determining the mechanical characteristics of bituminous mixtures made of BA or Hydrated Lime (HL) as filler. The results obtained in their work indicate that bituminous mixtures with a filler made of $70 \%$ BA and $30 \%$ HL fulfil European standards.

\subsection{Objective and scope}

Considering the above-mentioned scarce available literature and given that in Italy calcareous and cement fillers are normally used, the scope of the experimentation described in this paper is to evaluate the use of recycled fillers in bituminous mixtures for road pavements. For this reason, the laboratory investigation was devoted to assessing the performance of such mixtures for intermediate (binder) layers courses in which we used two different recycled materials as fillers. 
These materials come from a municipal solid incinerator (Stabilized Bottom Ashes SBAs) and Electric Arc Furnace (Electric Arc Furnace Steel Slags EAFSSs).

We verified the suitability of these materials as fillers for bituminous mixtures through a laboratory investigation, in which we considered two filler dosages. We also included in the investigation bituminous mixtures made of standard (calcareous) filler, for comparative purposes.

The laboratory comparison was based on the assessment of the compaction and volumetric properties and the final mechanical performance of the studied bituminous mixtures.

\section{Experimentation}

\subsection{Materials}

The key materials used in the experiments were:

- 50/70 penetration neat bitumen (EN 12591) [30], obtained from an Italian refinery;

- calcareous aggregates in the range of 0.063-25 mm provided by a local contractor;

- filler (0-0.063 mm):

I. calcareous filler,

II. Stabilized Bottom Ashes (SBAs) from incineration of unsorted municipal solid waste (MSW) collected throughout the territory (Lombardy, Italy) ${ }^{1}$

III. Electric Arc Furnace Steel Slags (EAFSSs) from an Italian steel industry.

Starting from the above-mentioned key materials, we prepared in the laboratory six bituminous mixtures: two for each of the three fillers, using filler/bitumen ratios equal to 1 and 2.

\subsection{Mixtures and specimen preparation}

We obtained the recycled fillers in the laboratory by crushing the slags using the Los Angeles apparatus (LA). We then washed (with water) the powder obtained after 2000 cycles (20 steel balls) of the LA and sieved it at $0.063 \mathrm{~mm}$.

The general appearance of the prepared fillers is shown in Figure $1(\mathrm{a}-\mathrm{c})$. The figure also shows a close-up image of the fillers obtained by Scanning Electron Microscope (SEM) (d-f). The figure shows that crystals can be seen in the calcareous filler; the SBA filler is characterized by a high degree of angularity; the EAFSS filler has an irregular shape with angular and flaky particles [31].

\footnotetext{
${ }^{1}$ Slags come from a single incinerator located in Lombardy. The original size distribution is reported in [11]
} 

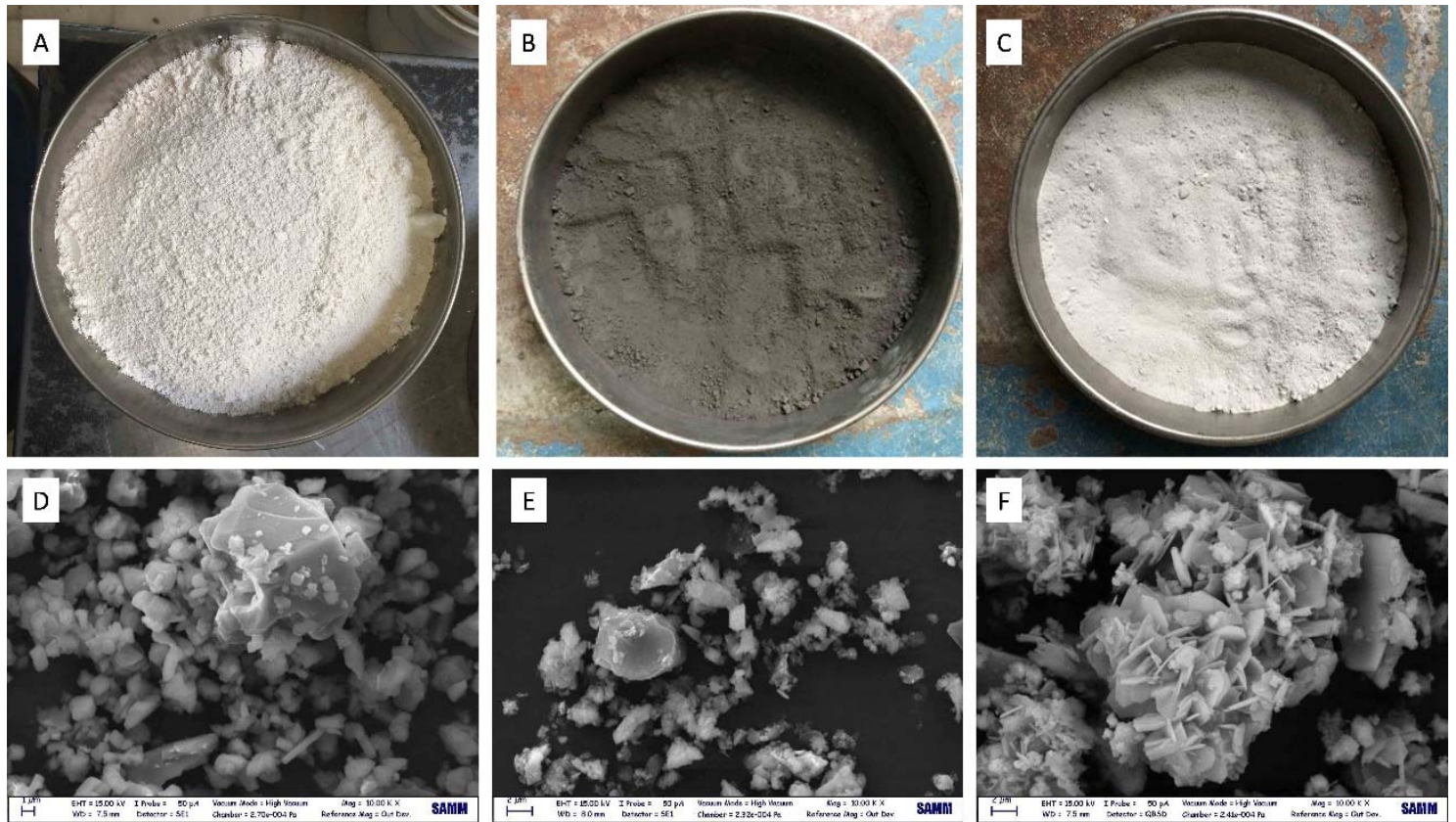

Figure 1: General appearance of Calcareous (A), SBA (B) and EAFSS (C) fillers; SEM images of Calcareous (D), SBA (E) and EAFSS (F) fillers. The scale bar at the bottom represent $1 \mu \mathrm{m}$.

As mentioned above, we considered two filler dosages, in order to obtain filler-bitumen mass ratios equal to 1 and 2 respectively. The aim was to highlight the differences in behavior of bituminous mixtures made with the two fillers. We determined the composition of asphalt mixtures, included in the experimental investigation, in line with the current specifications for binder (intermediate) courses provided by the Italian Road Authority - ANAS (Figure 2) [32]. Obviously, with a bitumen-filler ratio equal to 2 the sieve size distribution exceeds the ANAS specification limits; however, this is not relevant for the research purposes of this paper which was to highlight the effects of recycled filler type and dosage.

Therefore, we used the $50 / 70$ neat bitumen as binder at $5 \%$ by aggregate weight, complying with the minimum and maximum limits (between $4 \%$ and 5,3\%, respectively) defined by the same Italian Road Authority for intermediate (binder) layers. 


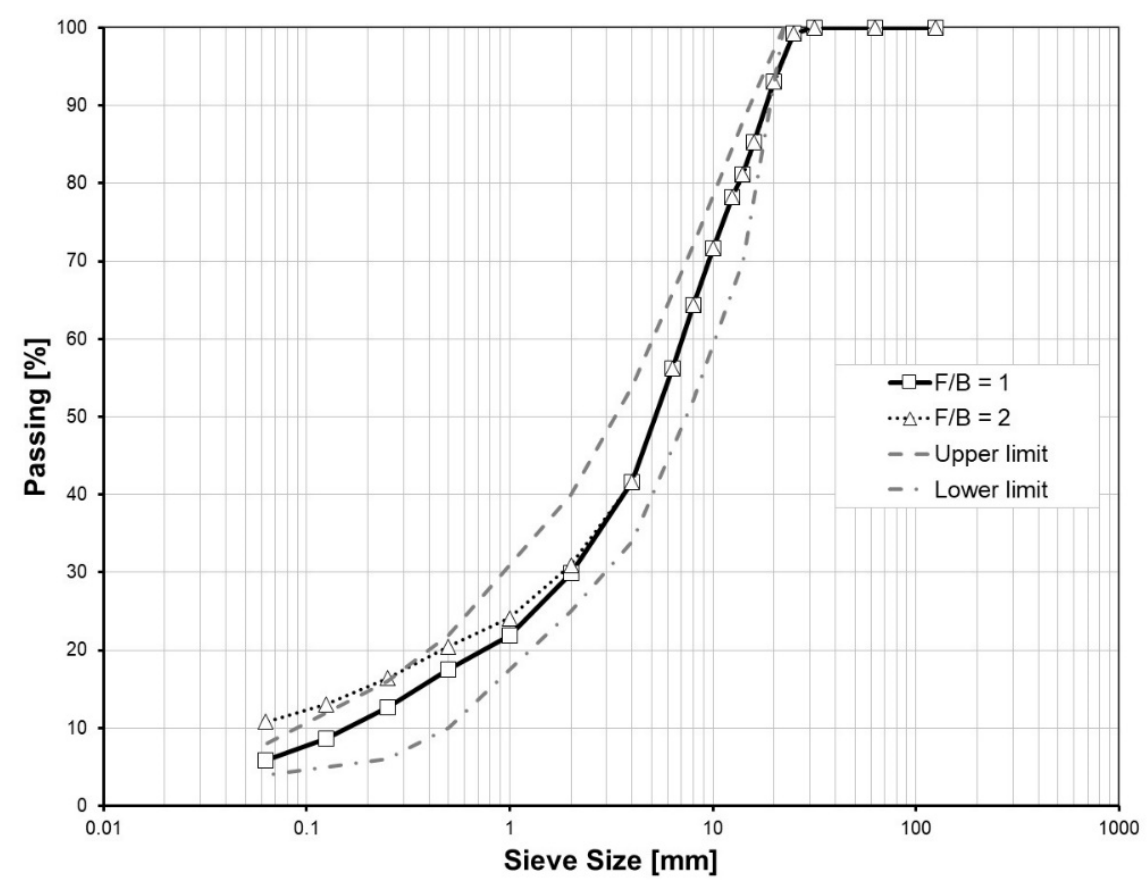

Figure 2: Gradation of the aggregates in bituminous mixtures as a function of the filler-bitumen ratio

We obtained two different mixtures using only calcareous filler (reference mixture having two filler/bitumen ratios), two mixtures with sieved SBAs in replacement of calcareous filler and two mixtures with sieved EAFSSs in replacement, again, of calcareous filler.

We prepared the bituminous mixtures using a heated laboratory mixer (16 kg/batch). Mixing temperature was $170 \pm 5{ }^{\circ} \mathrm{C}$, according to existing literature [33]; we produced a mass of $32 \mathrm{~kg}$ for each type of mixture.

To prevent formation of lumps of filler and to obtain a homogeneous final mixture, we used a method previously developed by the authors [34-35] and summarized in the following steps:

- heating of the aggregates, filler and bitumen to the mixing temperature;

- insertion of the aggregates in the mixer and addiction of bitumen;

- mixing of all the materials until the aggregates are homogeneously covered by the bitumen;

- addition of filler (about 10 grams at a time) while the mixer is still on;

- a final, five-minute mix.

The method described above produces a homogeneous mixture, as verified by a visual inspection, according to EN 12697-35. Then, we verified grain size distribution and bitumen content (by solvent extraction) and we measured the Theoretical Maximum Density (EN 12697-5) [36] on the loose mixtures. 
We prepared the specimens using a Gyratory Shear Compactor (GSC), in agreement with the protocol specifications defined within the Strategic Highway Research Program [37] (1,25 gyration angle, 30 rev $\mathrm{min}^{-1}$ gyration speed, $600 \mathrm{kPa}$ vertical pressure, $150 \mathrm{~mm}$ mold diameter).

We compacted nine cylindrical specimens of each mixture at the temperature of $160 \pm 5{ }^{\circ} \mathrm{C}$ using GSC mentioned above. We applied 100 compaction revolutions to each specimen. This, because previous studies showed that this value leads to density levels similar to those obtained in the field by standard compaction equipment and procedure [38]. During the GSC compaction, we measured the self-compaction $\mathrm{C}_{1}$ and workability $\mathrm{k}$ parameters. These parameters are used by pavement engineers to quantify the compaction properties and to compare different mixtures [39-40].

\subsection{Testing methods}

The experimental activity involved several tests selected to evaluate the volumetric characteristics and the performance-related properties of the bituminous mixtures, useful for assessing the role of non-conventional fillers (sieved SBAs and EAFSSs) in replacement of the traditional calcareous filler.

As for the volumetric characteristics, we carried out a complete volumetric characterization for all the GSC compacted specimens, including the analysis of overall voids (v\%), voids in the mineral aggregate (VMA) and voids filled with bitumen (VFB), according to EN 12697-8 [41]. In fact, only analyzing these three parameters a complete description of the mixtures in the compacted state is possible. Specifically, it can be stated that while $\mathrm{v} \%$ provides the measure of the degree of compaction achieved for a given mixture, being in relation to its density, the values VMA and VFB allow a better understanding of its internal structure: VMA assesses the degree of packing of the aggregate particles, while VFB gives the degree of voids filling caused by the effective bituminous binder.

As the core of the experimental investigation, we carried out mechanical tests to analyze the stiffness behavior and the failure properties of the mixtures. We performed the tests using an indirect tensile mode at three different temperatures $\left(5,20,40^{\circ} \mathrm{C}\right)$.

We adopted the indirect tensile mode, obtained by subjecting a cylindrical specimen to diametrical compression (Figure 3), to measure both the so-called stiffness modulus SM and the indirect tensile strength (ITS). We carried out both types of tests using a pneumatically driven asphalt tester in a temperature-controlled chamber.

As mentioned, we compacted 9 samples for each mixture. 3 of each have been used to assess stiffness at one of the three testing temperatures. The same samples were then tested up to failure performing 
an indirect tensile test at each relevant temperature. This could be done because of the small deformations applied during stiffness tests.
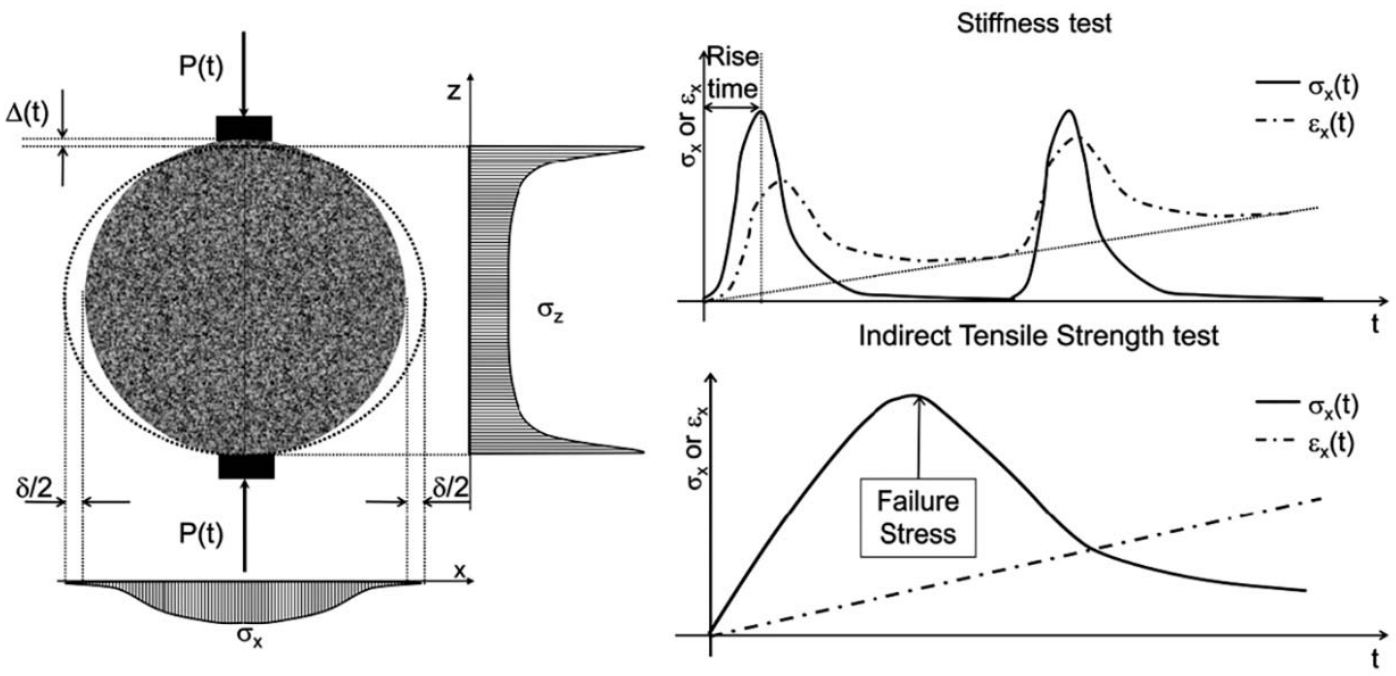

Figure 3: Test mode for the indirect tensile evaluation of both stiffness and failure indirect tensile strength

We measured the stiffness modulus in compliance with the EN 12697-26 - Annex C [42] at four frequency levels $(0.5,1,2,4 \mathrm{~Hz})$, as showed in Figure 4.

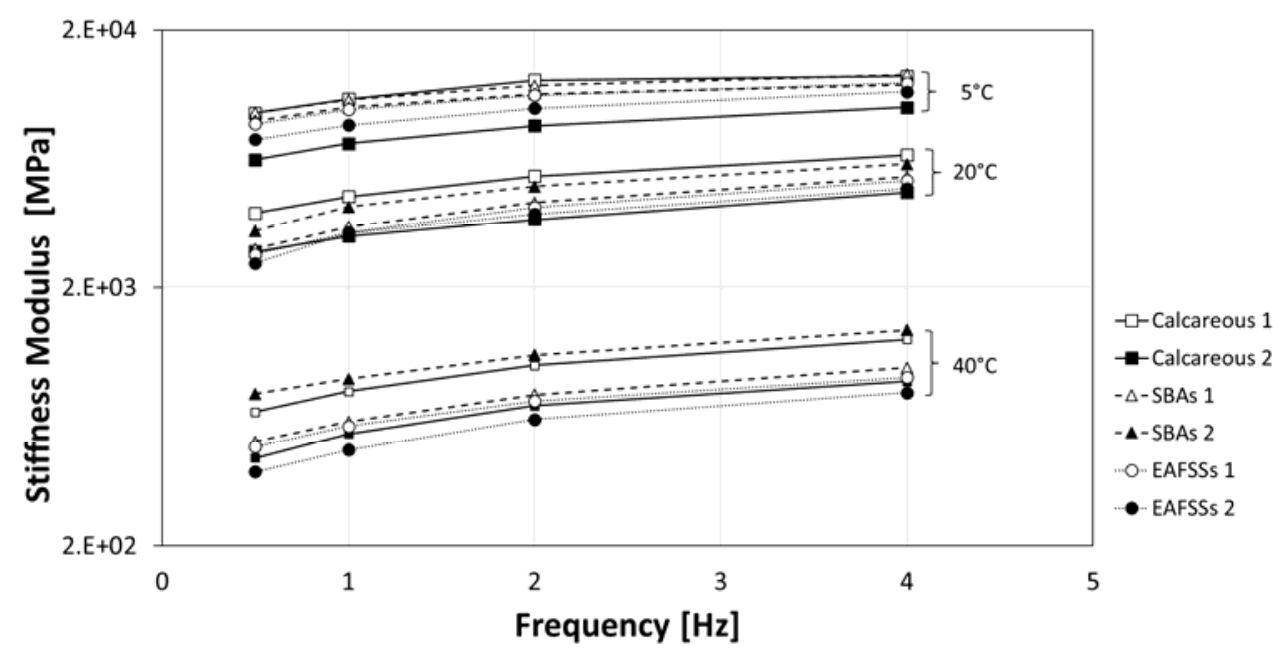

Figure 4: Stiffness Modulus of the investigated mixtures (5, 20, $40^{\circ} \mathrm{C}$ and $\left.0.5,1,2,4 \mathrm{~Hz}\right)$

In order to increase the frequency domain of the stiffness and to obtain more information about the behavior of the mixtures in a wide range of load frequencies, we used the stiffness measures to calculate the so-called master curves, using the numerical method proposed by Pellinen and Witczak 
[43]. We took $20^{\circ} \mathrm{C}$ as the reference temperature, using the following relationship between the load frequency and the temperature:

$$
\log \left(f_{r}\right)=\log (f)+\log \left(\alpha_{t}\right)
$$

Where:

- $f$ is the load frequency of the test $[\mathrm{Hz}]$;

- $f_{r}$ is the reduced frequency (in line with the reference temperature), [Hz];

- $\alpha_{t}$ is the shift factor, based on the theory of Arrhenius.

We then applied the sigmoidal model (by Pellinen and Witczak) to get the so-called master curves:

$$
\log (\text { SM PW models })=\log \left(a_{0} \cdot\left(1-e^{-\frac{f_{r}}{a_{1}} a_{2}}\right)\right)
$$

Where:

- $a_{0}, a_{1}, a_{2}$ are shape parameters;

- $f_{r}$ is the reduced frequency $[\mathrm{Hz}]$;

- $\quad$ SM PW models is the Stiffness Modulus applying the Pellinen and Witczak model [MPa].

We investigated the failure properties using the Indirect Tensile Strength (ITS) test in line with the European specifications (EN 12697-23 2003) [44].

\section{Results and discussion}

Figures 5, 6, 8 and 9 show the experimental results (compaction properties, volumetric characteristics and failure performance) as a function of both filler type and dosage (expressed as filler/bitumen ratio). The error bars on the graphs display the maximum and minimum value obtained for each mixture. Figure 7 reports the master curves to display the stiffness behavior of the mixtures.

\subsection{Compaction properties}

Compaction parameters $\left(\mathrm{k}\right.$ and $\mathrm{C}_{1}$ ), reported in Figure 5, show that recycled filler does not significantly affect the compaction properties of the corresponding bituminous mixtures. Both the proneness to be compacted under the paver during laying operations (Self-Compaction $\mathrm{C}_{1}$ ) and the ability to achieve a stable stone-to stone contact under the rollers (Workability k) of the mixtures with 
non-conventional filler, are not significantly different if compared to the same properties of the reference mixture in which the lower amount of calcareous filler $(\mathrm{f} / \mathrm{B}=1)$ is used. As for the other reference mixture (calcareous filler, $\mathrm{F} / \mathrm{B}=2$ ), in which an excess of this filler could be the reason why the mixture reveals a high value of $\mathrm{C}_{1}$, the results are quite different: the mixture is not stable, thus it is not able to maintain its shape under the paver action, reducing the internal voids before the roller compaction. It is also confirmed by the reduction of the workability $(\mathrm{k})$ : there is no room into the mixture during the roller compaction and, thus, for the reorganization of the aggregates.
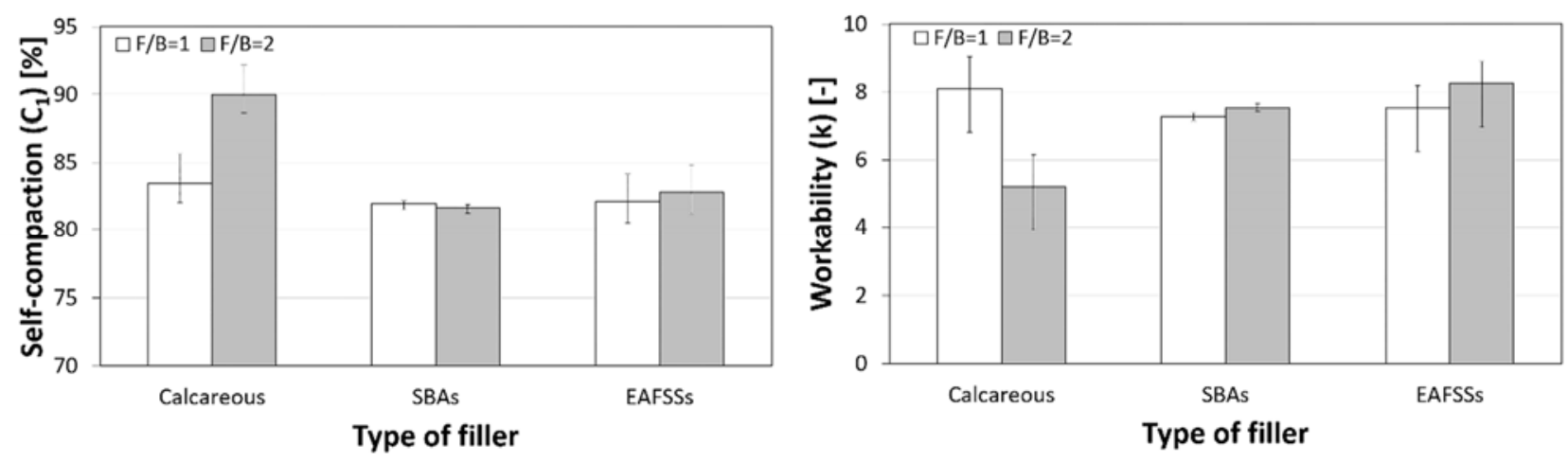

Figure 5: Compaction properties of the investigated mixtures

\subsection{Volumetric characteristics}

Figure 6 shows how non-conventional fillers affect the volumetric characteristics of the mixtures.

It would seem that with increasing amount of filler, the voids content decreases for the two mixtures with recycled filler, as opposite to the behavior of the mix with calcareous filler. Yet variations are small compared to experimental data scatter and the observed differences may not be significant.

Figure 6 also shows that, in the mixtures with SBAs, VMA, which assess the degree of packing of the aggregate particles, increases with increasing filler content; an opposite trend is observed for the mixtures with EAFSSs. Also for VFB, which gives information about the content of voids in the aggregates filled by bitumen, the two types of recycled filler display opposite trends with increasing filler content, although differences again are very small.

In mixtures containing calcareous filler, filler/bitumen ratio does not significantly affect the three parameters $(\% \mathrm{v}, \mathrm{VMA}$ and VFB).

Overall, the volumetric characteristics of the investigated mixture are quite similar and not influenced by filler type, whether conventional (calcareous) or recycled (SBAs and EAFSSs). 

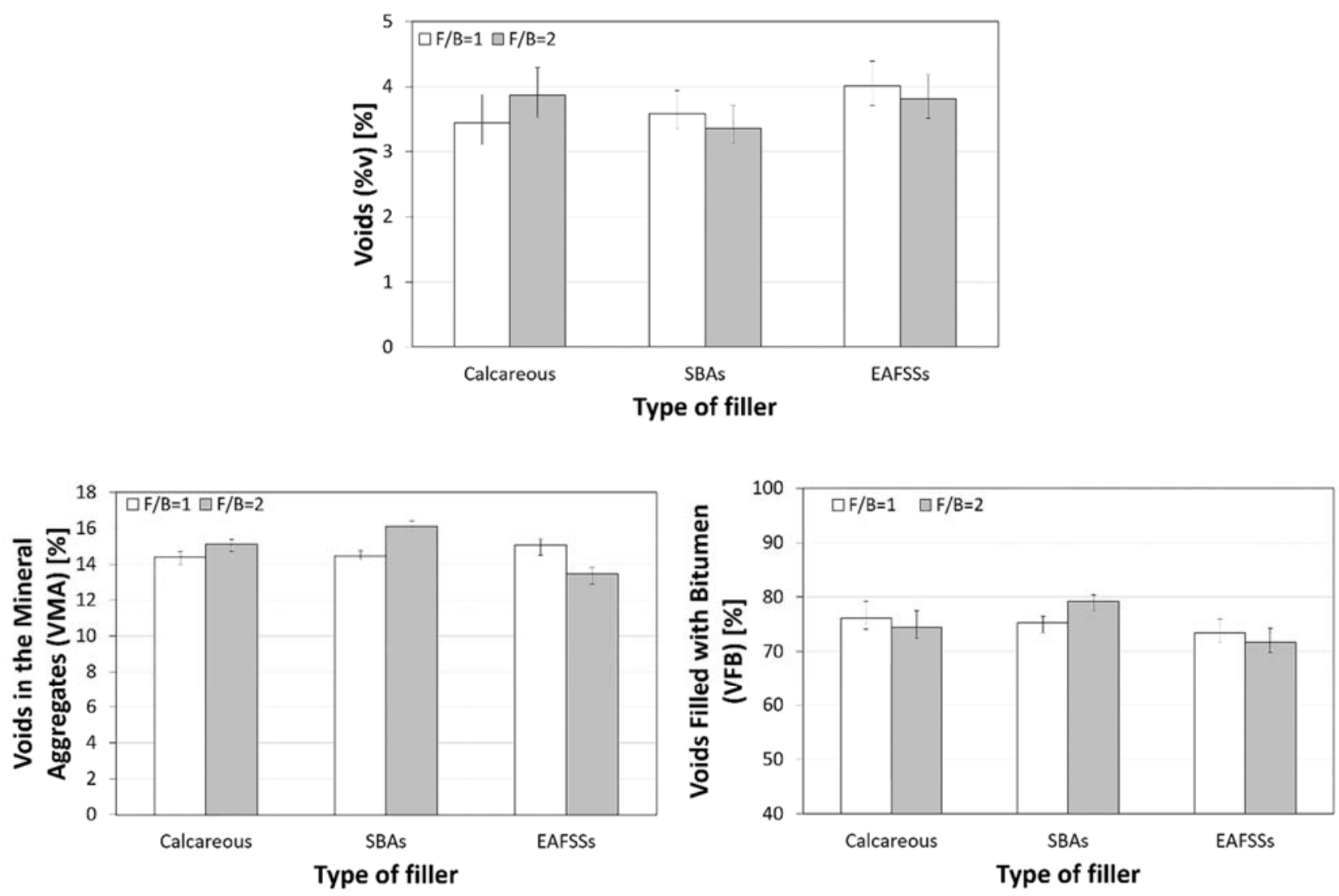

Figure 6: Volumetric characteristics of the investigated mixtures

\subsection{Mechanical performance}

The following figures show both Stiffness Master Curves (SMC) and ITS results.

The SMC for the six mixtures, plotted in Figure 7, show a fair degree of correspondence between test data and the values described by the model.

It is important to note that for all the mixtures analyzed in the study, for a given filler/bitumen ratio, the stiffness is almost the same, and, in general, mixtures with $\mathrm{F} / \mathrm{B}=1$ display higher stiffness. Anyway, it is possible to make some preliminary observations:

- $\mathrm{F} / \mathrm{B}=1$ : the mixture with conventional calcareous filler is consistently stiffer than the one with EAFSSs over the investigated range of frequencies; the one with SBAs filler has an intermediate behavior, closer to EAFSSs at low frequencies and increasing at high frequencies;

- $\mathrm{F} / \mathrm{B}=2$ : for higher filler content, the stiffness decreases slightly for all fillers; yet, the decrease is way more evident for the mixture with calcareous filler, which has the lowest stiffness over the whole frequency range investigated. The highest stiffness was observed for the mixture with SBAs while the one with EAFSSs falls in between the other two. 
We used all the specimens subjected to stiffness test to measure the ITS at 5, 20 and $40^{\circ} \mathrm{C}$. The average experimental results with dispersion bars, plotted in Figure 8, show that ITS decreases with increasing temperature, as expected. However, it is important to point out that while in mixtures containing SBAs and EAFSSs, ITS increases with the increase of the filler-bitumen ratio, in mixtures with calcareous filler, a maximum value of ITS, for each temperature, is observed with a fillerbitumen ratio equal to one.

Furthermore, it is important to underline that, with $\mathrm{F} / \mathrm{B}=2$, the maximum values of ITS, for each temperature, are reached by the mixtures with recycled fillers. However, with $\mathrm{F} / \mathrm{B}=1$, ITS decreases if SBAs or EAFSSs are used in replacement of traditional filler.

In order to compare the behavior of mixtures with recycled fillers to the reference one, we also calculated the ITS ratio, as the ratio between the ITS of a given mixture (for a certain recycled filler dosage) and the reference one (at the same filler dosage) for each temperature $\left(5,20,40^{\circ} \mathrm{C}\right)$. This coefficient is plotted in Figure 9.

$$
\text { ITS ratio }=\frac{I T S_{\text {mixture } i}}{I T S_{\text {calcareous }}}
$$

This coefficient shows that, for $\mathrm{F} / \mathrm{B}=1$ the mixture with calcareous filler has always the best performance in terms of ITS. On the contrary, for $\mathrm{F} / \mathrm{B}=2$, the mixtures containing recycled fillers are in generally better than the reference mixture. In particular, the SBAs mixture $(\mathrm{F} / \mathrm{B}=2)$ has significantly higher performance (in failure properties) than the reference, for test at 20 and $40^{\circ} \mathrm{C}$. 
a)

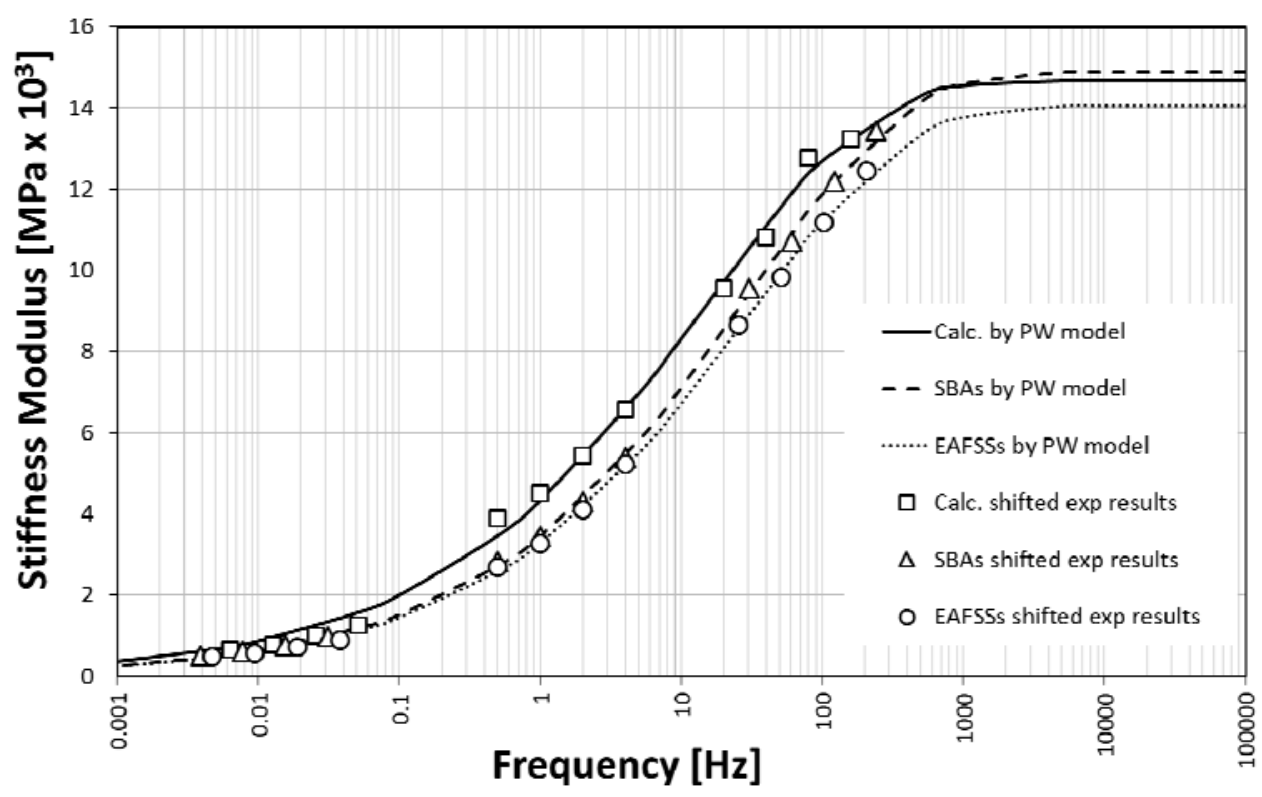

b)

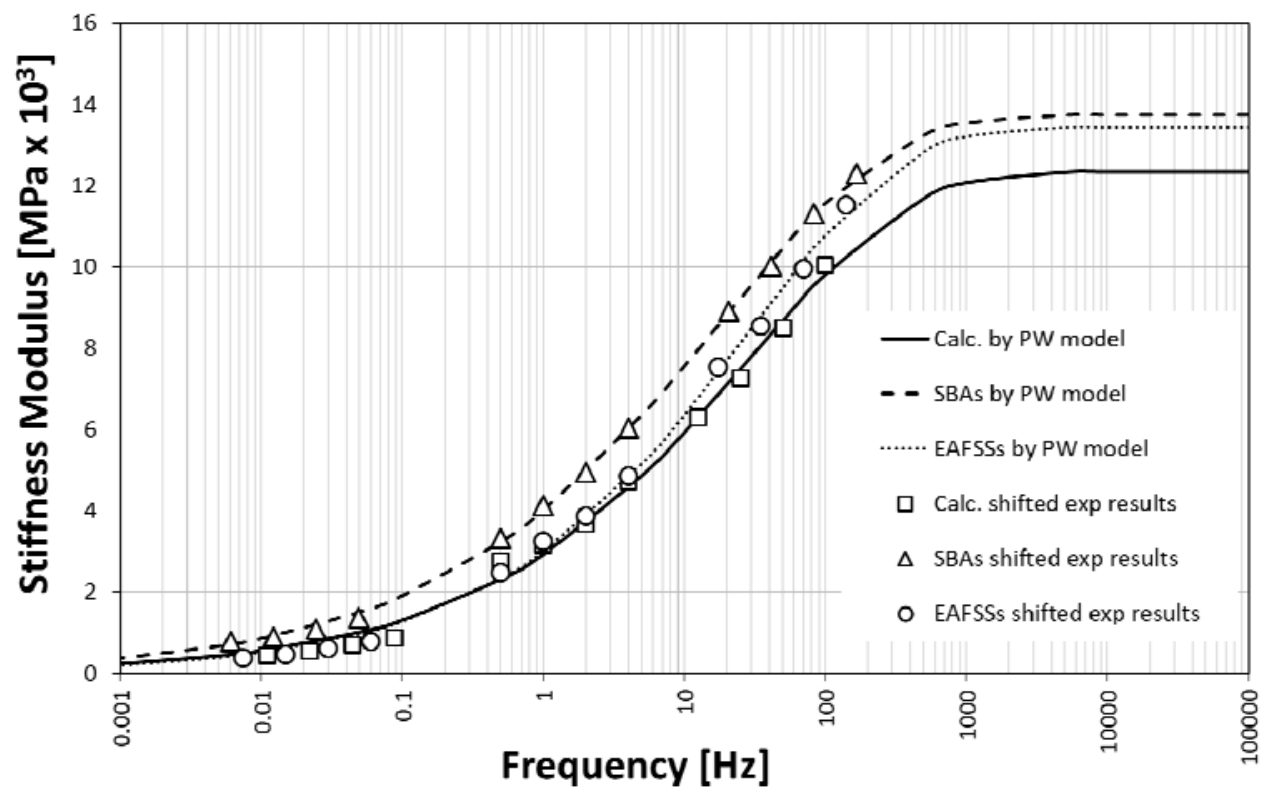

Figure 7: Stiffness master curves at $20^{\circ} \mathrm{C}$ for the investigated mixtures. a) $F / B=1, b$ ) $F / B=2$ 


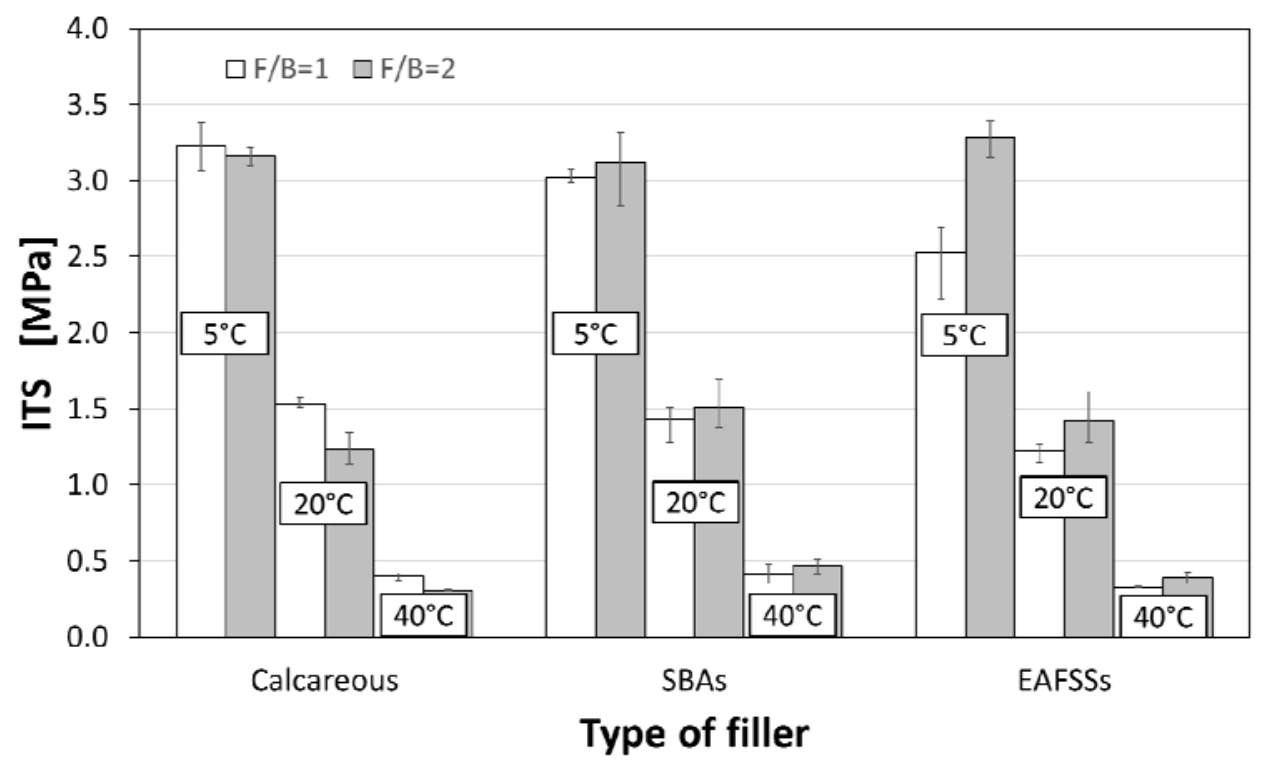

Figure 8: Indirect tensile strength of the investigated mixtures

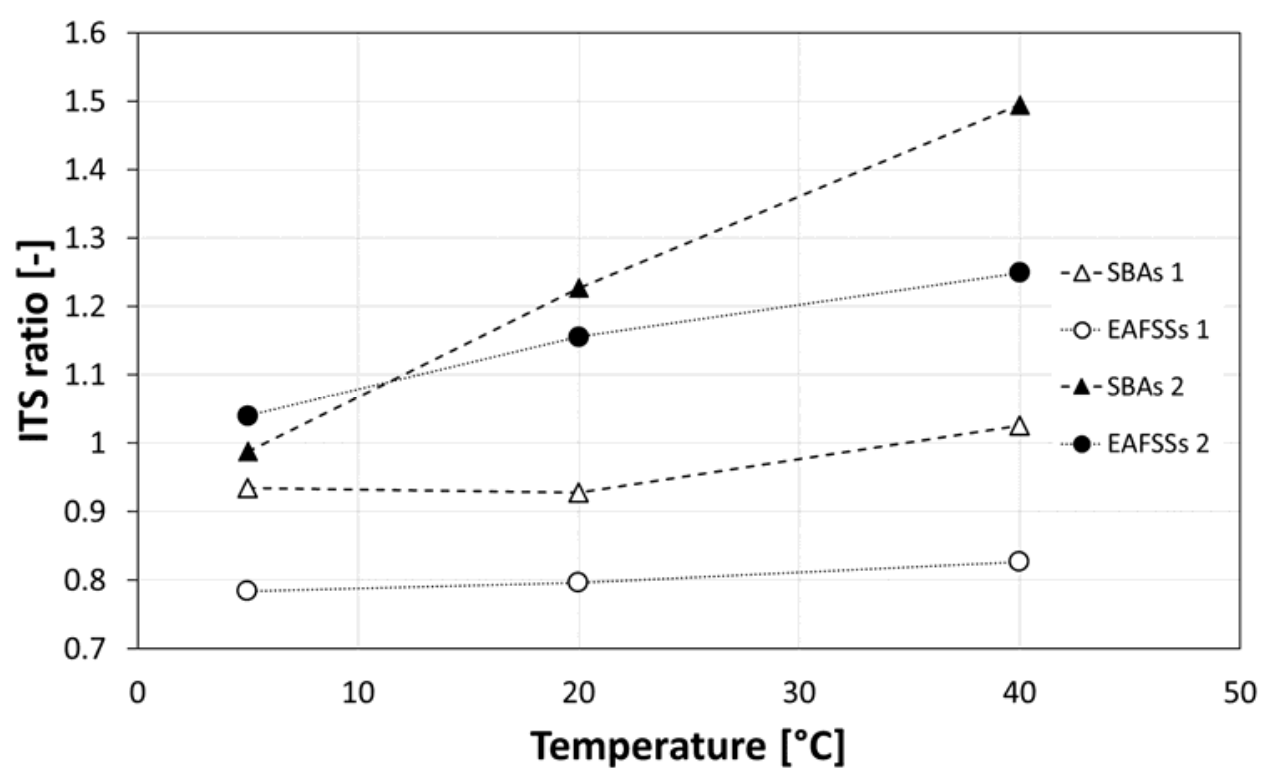

Figure 9: ITS ratio (to calcareous filler with equal dosage) of the mixtures prepared from recycled fillers

Other interesting remarks can be obtained analyzing the SMC at the respective temperature (high, intermediate and low), in order to highlight their performance complying with the pavement distresses in the field.

Taking into account this general consideration, and using the time-temperature superposition principle, we can read the SMC results considering that the stiffness at low frequencies are associated to high temperatures, and the vice versa is true for high frequencies (low temperatures). 
Following this point of view, it is useful to consider that the distress that typically occurs at high temperature is rutting, a road surface depression in the wheel path. This pavement distress, that may be caused by plastic movement of the bituminous matrix, is due to the simultaneous effect of traffic loads and hot weather. To prevent this phenomenon, is desirable to reach a high stiffness at low frequencies (high in-service temperatures). On this basis, low frequencies SMC results reveal that recycled fillers do not significantly affect the stiffness results. Rather, mixtures with the higher amount of EAFSS filler $(\mathrm{F} / \mathrm{B}=2)$ guarantee the best performance.

Regarding intermediate temperatures (or intermediate frequencies), pavement engineers commonly use mechanical performance of the bituminous mixtures as input to design road pavement and predict the fatigue life of a bituminous layer. In general, there is not a desirable value or range of stiffness, because it depends on the number, thickness and bearing capacity of the layers that compose the road pavement. Due to that, we can observe that when we use the lower amount of filler $(\mathrm{F} / \mathrm{B}=1)$, the recycled materials show the lower stiffness. On the contrary, at the higher filler content $(F / B=2)$, the recycled materials increase their stiffness, particularly when SBAs are used.

As for low temperatures, transverse cracks are the typical distresses that, during winter, occur on the surface layers of a road pavement, and it is generally due to a sudden reduction in temperature between daytime and night. To prevent these distresses, the pavement layers should be characterized by a low value of stiffness.

Consequently, the mixture in which EAFSS shows the best performance, is the one at the lower filler content $(\mathrm{F} / \mathrm{B}=1)$, whereas the calcareous filler seems to work better at the higher dosage of filler $(\mathrm{F} / \mathrm{B}=2)$. However, it must be considered that this mixture had some troubles during compaction (high self-compaction and scarce workability), so it is possible that the positive results at low and intermediate temperatures (or frequencies) are due to a bad compaction. In other words, the compaction was not able to guarantee the stone-to-stone contacts into the bituminous matrix, reducing the ability of the mixture to share the stress and thus reducing its Stiffness.

The same two filler/bitumen ratios (1 and 2) were chosen for three filler types, to allow for a direct comparison of relevant mixtures. However, in view of the obtained results, it would be interesting to determine the optimal content in the case of recycled fillers, to fully ascertain their potential performance in the field. 


\section{Conclusions}

The comparative laboratory investigation described in this paper focused on the effects of recycled materials (Stabilized Bottom Ashes (SBAs) from municipal waste incinerators and Electric Arc Furnace Steel Slags (EAFSSs) as filler in bituminous mixtures used as intermediate (binder) courses. The analysis aimed at investigating compaction properties, volumetric characteristics, and mechanical performance of the bituminous mixtures.

Based on the results reported in this paper, we can draw the following conclusion: it is possible to use the investigated non-conventional (recycled) materials as filler in bituminous mixtures.

In fact, as widely described above, the compaction properties, the volumetric characteristics and, especially, the mechanical performances are similar, or even better, of those obtained for the same mixture containing standard (calcareous) filler. From a field point of view, both compaction and volumetric tests demonstrated that no special precautions are necessary to obtain adequate volumetric characteristics and, thus, mechanical performance.

Additional investigations could further support these findings. In particular, it would be interesting to verify the effects of these fillers not only on the properties of the final mixtures but also on the corresponding bituminous mastics. Also, other mechanical properties need to be considered, including fatigue and rutting behavior of the corresponding mixtures in which these fillers are included. Finally, the production methods of such recycled fillers and their use in the mixing plants for bituminous mixtures must be studied before they could be used at the real scale. 


\section{Acknowledgements}

The research was supported by Road Research Laboratory (RRL) and Advanced Manufacturing Lab (AMALA) of Politecnico di Milano. 


\section{References}

[1] Directive 2008/98/EC on waste and repealing certain Directives, European Parliament and Council, 2008

[2] COM 2020: EUROPE 2020 A strategy for smart, sustainable and inclusive growth, European Commission, 2010

[3] COM 571: Roadmap to a Resource Efficient Europe, European Commission, 2011

[4] A. Demirbas, Waste Management, waste resource facilities and waste conversion processes, Energy Conversion and Management 52 (2011) 1280-1287.

[5] R. Cioffi, F. Colangelo, F. Montanaro, L. Santoro, Manufacture of artificial aggregate using MSWI bottom ash, Waste Management 31 (2011) 281-288.

[6] M. T. Eymael, W. De Wijs, D. Mahadew, The use of MSWI bottom ash in asphalt concrete, Studies in Environmental Science 60 (1994) 851-862.

[7] F. Giustozzi, E. Toraldo, M. Crispino, Recycled airport pavements for achieving environmental sustainability: An Italian case study, Resources, Conservation and Recycling 68 (2012) 67-75.

[8] M. Magnoni, E. Toraldo, F. Giustozzi, M. Crispino, Recycling practies for airport pavement construction: Valorisation of on-site materials, Construction and Building Materials 112 (2016) 59-68.

[9] S. Jayakody, C. Gallage, A. Kumar, Assessment of recycled concrete aggregates as a pavement material, Geomechanics and Engineering 6 (2014) 235-248.

[10] A. M. Nicuţă, Featuring reclaimed asphalt pavement integration in warm mix asphalt towards roads sustainable development, Advance Materials Research 649 (2013) 242-245

[11] E. Toraldo and S. Saponaro, A road pavement full-scale test track containing stabilized bottom ashes, Environmental Technology (2014).

[12] E. Toraldo, S. Saponaro, A. Careghini, E. Mariani, Use of stabilized bottom ash for bound layers of road pavements, Journal of Environmental Management 121 (2013) 117-123.

[13] M. Pasetto, N. Baldo, Laboratory investigation on foamed bitumen bound mixtures made with steel slag, foundry sand, bottom ash and reclaimed asphalt pavement, Road Materials and Pavement Design 13:4 (2010) 691-712.

[14] T. Sabbas, A. Polettini, R. Pomi, T. Asprup, O. Hjelmar, P. Mostbauer, G. Cappai, S. Salhofer, C. Speiser, S. Heuss-Assbichler, R. Klein, P. Lechner, Management of municipal solid waste incineration residues, Waste Manage 23 (2003) 61.

[15] L. Reijnders, Disposal, uses and treatments of combustion ashes: a review, Resour Conserv Recy 43 (2005) 313. 
[16] S. Sorlini, A. Abbà, C. Collivignarelli, Recovery of MSWI and soil washing residues as concrete aggregates, Waste Management 31 (2011) 289-297.

[17] R. Siddique, Use of municipal solid waste ash in concrete, Resources, Conservation and Recycling 55 (2010) 83-91.

[18] J. R. Pan, C. Huang, J. J. Kuo, S. H. Lin, Recycling MSWI bottom and fly ash as raw materials for Portland cement, Waste Management 28 (2008) 1113-1118.

[19] M. M. Hassan, H. Khalid, Mechanical and environmental characteristics of bituminous mixtures with incinerator bottom ash aggregates, International Journal of Pavement Engineering 11 (2010) 83-94.

[20] D. L. Gress, X. Zhang, S. Tarr, I. Pazienza, T. T. Eighmy, Municipal Solid Waste Combustion ASH as an Aggregate Substitute in Asphaltic Concrete, Studies in Environmental Science 48 (1991) 161-175.

[21] O. Akinmusuru, Potential beneficial uses of steel slag wastes for civil engineering purposes, Resources, Conservation and Recycling 5 (1991) 73-80.

[22] M. Pasetto, N. Baldo, Experimental evaluation of high performance base course and road base asphalt concrete with electric arc furnace steel slags, Journal of Hazardous Materials 181 (2010) 938-948.

[23] S. Sargın, M. Saltan, N. Morova, S. Serin, S. Terzi, Evaluation of rice husk ash as filler in hot mix asphalt concrete, Construction and Building Materials 48 (2013) 390-397.

[24] U. Rongali, G. Singh, A. Chourasiya, Dr.P.K.Jain, Laboratory investigation on use of fly ash plastic waste composite in bituminous concrete mixtures, Procedia - Social and Behavioral Sciences 104 ( 2013) 89-98.

[25] R.K. Dhir, L.J. Csetenyi, T.D. Dyer, G.W. Smith, Cleaned oil-drill cuttings for use as filler in bituminous mixtures, Construction and Building Materials 24 (2010) 322-325.

[26] M. Chen, J. Lin, S. Wu, Potential of recycled fine aggregates powder as filler in asphalt mixture, Construction and Building Materials 25 (2011) 3909-3914.

[27] M. Pasetto, A. Baliello, G. Giacomello, E. Pasquini, Rheological Characterization of WarmModified Asphalt Mastics Containing Electric Arc Furnace Steel Slags, Advances in Materials Science and Engineering (Volume 2016, Article ID 9535940,) 1-11.

[28] M. Arabani, S Tahami, M. Taghipoor, Laboratory investigation of hot mix asphalt containing waste materials, Road Materials and Pavement Design (2016) 1-17.

[29] E. López- López, Á. Vega-Zamanillo, M. Á, Calzada-Pérez, M.A. Taborga-Sedano, Use of bottom ash from thermal power plant and lime as filler in bituminous mixtures, Materiales de Costrucción 65 No 318 (2015) 1-6. 
[30] EN 12591 Bitumen and bituminous binders - SPECIFICATIONS for paving grade bitumens, European Committee for Standardization, 2009.

[31] V. Antunes, A. C. Freire, L. Quaresma, R. Micaelo, Effect of the chemical composition of fillers in the filler-bitumen interaction, Construction and Building Materials 104 (2016) 8591.

[32] Capitolato speciale d'appalto, Parte 2 Norme tecniche, Pavimentazioni stradali/autostradali ed. 2010, ANAS S.p.A. (Italian Road Specifications).

[33] Asphalt Institute, The Asphalt Handbook, MS-4, $7^{\text {th }}$ ed. 2007.

[34] E. Toraldo, E. Mariani, S. Malvicini, Laboratory investigation into the effects of fibers on bituminous mixtures, Journal of Civil Engineering and Management 21 (2015) 45-53.

[35] C. Bonica, E. Toraldo, L. Andena, C. Marano, E. Mariani, The effects of fibers on the performance of bituminous mastics for road pavements, Composites Part B 95 (2016) 7681.

[36] EN 12697-5 Bituminous mixtures - test methods for hot mix asphalt - Part 5: Determination of the maximum density, European Committee for Standardization, 2010.

[37] The Superpave mix design system, Manual of specifications, test methods and practices, Strategic Highway Research Program SHRP A-379, Washington DC, USA, National Research Council, 1994.

[38] M. Bassani, E. Santagata, Full-scale investigation on the volumetric relationship between laboratory and in-situ compaction, in Proc. of the $3^{\text {rd }}$ International Conference on "Bituminous Mixtures and Pavements", Tessaloniki, Greece, 2002.

[39] M. Bassani, E. Santagata, Construction: roofing, waterproofing and bituminous materials, in Proc. of the $3^{\text {rd }}$ International Conference on "Bituminous Mixtures and Pavements", Tessaloniki, Greece, 2002.

[40] R. Cominsky, R. B. Leahy, E. T. Harrigan, Level one mix design: material selection, compaction, and conditioning, Strategic Highway Research Program SHRP A-408, Washington DC, USA, National Research Council, 1994.

[41] EN 12697-8 Bituminous mixtures - test methods for hot mix asphalt - Part 8: Determination of voids characteristics of bituminous specimens, European Committee for Standardization, 2003

[42] EN 12697-26 Bituminous mixtures - test methods for hot mix asphalt - Part 26: Stiffness, European Committee for Standardization, 2004. 
[43] T. K. Pellinen, M. W. Witczak, Stress dependent master curve construction for dynamic complex modulus, Asphalt paving technology: association of asphalt paving technologists, Proc. Tech Session 71 (2002) 281-309.

[44] EN 12697-23 Bituminous mixtures - test methods for hot mix asphalt - Part 23: Indirect Tensile Strength, European Committee for Standardization, 2003. 